\title{
SCIDiC
}

\author{
International Journal of Dentistry and Oral Science (IJDOS) \\ ISSN: 2377-8075
}

\section{Incidence Of Re-Root Canal Treatment In Canines Due To Obturation Short Of Apex - A Retrospective Study}

Research Article

Nurul Syamimi binti Mohd Azlan Sunil ${ }^{1}$, Adimulapu Hima Sandeep ${ }^{2 *}$, Revathi Duraisamy ${ }^{3}$

${ }^{1}$ Saveetha Dental College and Hospitals, Saveetha Institute of Medical and Technical Sciences, Saveetha University, Chennai, India.

${ }^{2}$ Senior Lecturer, Department of Conservative Dentistry and Endodontics, Saveetha Dental College and Hospitals, Saveetha Institute of Medical and Technical Sciences, Saveetha University, Chennai, 600077, India.

${ }^{3}$ Senior Lecturer, Saveetha Dental College and Hospitals, Saveetha Institute of Medical and Technical Sciences, Saveetha University, Chennai, 600077, India.

\section{Abstract}

High rates of root canal treatment failure is due to inadequate canal preparation and obturation. Root canal treatment has a higher rate of success if the highest standard is followed when doing the treatment. Root canal failures in canines are most likely due to inadequate filling or under obturation as canines have the longest average root length compared to other teeth. The aim of this study was to evaluate the incidence of re-root canal treatment cases in canines due to obturation short of apex. This study includes adults, both males and females who reported to Saveetha Dental College from June 2019 to March 2020. Inclusion criteria included patients between the age of 18 to 40 years and patients who had undergone root canal treatment in canines. Patients below 18 years were excluded from the study. Around 86000 patient records were reviewed and analysed for the inclusion criteria and the following parameters were extracted; (i) patient's gender, (ii) tooth involved and (iii) reason for re-root canal treatment. Data was gathered and recorded into Microsoft Office Excel (2013) and analysed using SPSS software Version 26.0. Chi-square test was done to find out association in re-root canal treatment in canines due to obturation short of apex between variables such as gender and tooth involved. Significant test level was set at $\mathrm{p}<0.05$. A total of 17 re-root canal treatments in canines were found. This involved $58.8 \%$ females and $41.9 \%$ males. $64.7 \%$ of the re-root canal treatment in canines were due to obturation short of apex. $66.7 \%$ of mandibular canines and $64.2 \%$ of maxillary canines were re-root canal treated due to obturation short of apex. No significant association was found in re-root canal treatment in canines due to obturation short of apex between gender and tooth involved $(\mathrm{p}>0.05)$. Within the limits of this study, it was observed that the majority of root canal treated canines underwent retreatment is due to obturation short of apex. Most prevalent tooth to undergo retreatment due to obturation short of apex was mandibular canines.

Keywords: Canines; Endodontic Failures; Re-Root Canal Treatment; Root Canal Treatment; Under Obturation.

\section{Introduction}

The main goal of root canal treatment is to minimize and eliminate the microbes from root canal spaces by chemico-mechanical preparation and to promote periapical healing and prevent reinfection by sealing the root canal space [1]. Root canal treatment has a high rate of success if the highest standard is followed when doing the treatment. Previous studies reported the success rate of root canal treatment to be 90 to $95 \%[2,3]$.
Various reasons can contribute to failure in root canal treatment. Healing of the periapical region depends on the root canal filling quality. Kirkevang et al and Dugas et al reported high prevalence of periapical lesions in root canal treated with inadequate root canal filling $[4,5]$. Root canal preparation and filling that is confined to $0-2 \mathrm{~mm}$ from the radiographic apex is less likely to develop complications compared to obturation beyond pocket or short of apex [6]. Root canal obturations are considered adequate when there are no voids present between root canal fillings and root canal walls. According to the European Association of En-

*Corresponding Author:

Senior Lecturer, Department of Conservative Dentistry and Endodontics, Saveetha Dental College and Hospitals, Saveetha Institute of Medical and Technical Sciences, Saveetha University, Chennai, 600077, India.

Tel: +919003175288

E-mail: himas.sdc@saveetha.com

Received: November 10, 2020

Accepted: December 15, 2020

Published: December 18, 2020

Citation: Nurul Syamimi binti Mohd Azlan Sunil, Adimulapu Hima Sandeep, Revathi Duraisamy. Incidence Of Re-Root Canal Treatment In Canines Due To Obturation Short Of Apex - A Retrospective Study. Int J Dentistry Oral Sci. 2020;7(12):1252-1255. doi: http://dx.doi.org/10.19070/2377-8075-20000247

Copyright: Adimulapu Hima Sandeep 2020 . This is an open-access article distributed under the terms of the Creative Commons Attribution License, which permits unrestricted use, distribution and reproduction in any medium, provided the original author and source are credited. 
dodontics, a satisfactory root canal should be $0-2 \mathrm{~mm}$ short of radiographic apex to prevent root canal failure [7]. Root canal treatment failure due to persistence of microbes in the apical region of root even in well treated teeth are observed in the majority of cases. A study by Akbar et al reported that underfillings were found in $46.9 \%$ of root canals [8].

Canines have the longest average root length compared to other teeth. Somalinga et al studied the morphology of the root canal of maxillary and mandibular canine and observed that the average anatomical length of maxillary canine is $26.43 \mathrm{~mm}$ and mandibular canine is $24.21 \mathrm{~mm}$ [9]. Therefore, root canal failures in canine are most likely due to inadequate filling or under obturation.

Over the past 5 years, innumerable clinical trials [10-15], in-vitro studies [16-21] and article reviews [22-24] had previously been conducted by our team. Currently we are focusing on analysing re-root canal treatment due to obturation short of apex in canines. The aim of this study is to evaluate the incidence of re-root canal treatment in canines due to obturation short of apex.

\section{Materials And Methods}

This retrospective study involved adults, both males and females, who reported to a private dental college between June 2019 to March 2020. The study was conducted as a university-based study. This allowed flexible data retrieval, automated data collection and cost-effective. However, such setting only allowed a limited population to be covered and study may be subjected to researcher's personal bias. Data retrieval was approved by the Ethical Committee Board of the college with approval number of SDC/ SIHEC/2020/DIAS DATA/0619-0320. Patient's informed consent was obtained prior to clinical examination of the patients.

Around 86000 patient records between June 2019 to March 2020 were reviewed and analysed for re-root canal treatment in canines and the cases were cross-verified with treatment photographs and radiographs uploaded into the system. Patients with incomplete case sheets were exempted from the study. Simple random sampling was done to minimize sampling bias.

Data was collected by a single calibrated examiner. The inclusion criteria included patients with re-root canal treatment in canines. Patients below 18 years were excluded from the study. The following parameters were observed and recorded: (i) patient's gender, (ii) tooth involved and (iii) reason for retreatment.

\section{Statistical Analysis}

All the datas obtained were entered into Microsoft Office Excel (2013) and analysed using SPSS Software Version 26.0. Descriptive statistics were used to report distribution of gender, tooth involved and reason for retreatment. Chi-square test was conducted to find correlation between reason for retreatment and gender and tooth involved. Significance test level was set at $\mathrm{p}<0.05$.

\section{Results And Discussion}

A total of 17 root canal retreatment cases in canine was found. This involves 10 (58.8\%) female teeth and 7 (41.2\%) male teeth (Figure 1). 17.6\% were mandibular canines and $82.4 \%$ were maxillary canines (Figure 2). Out of 17 root canal retreatment in canines, $64.7 \%$ of cases were due to obturation short of apex and $35.3 \%$ was due to various reasons (Figure 3).

Based on gender, $70 \%$ of females underwent re-root canal treatment in canines due to obturation short of apex and $57.1 \%$ of males(Figure 4). There was no statistically significant association between re-root canal treatment in canines due to obturation short of apex and gender ( $>0.05)$ (Figure 4). Based on the tooth

Figure 1. Shows the graphical representation of the number of re-root canal treatment in canines by gender. X-axis represents gender (female- pink, malebrown) and $\mathrm{Y}$-axis represents the number of re-root canal treatment in canines. Re-root canal treatment in canines was higher in females(58.8\%) compared to males $(41.2 \%)$.

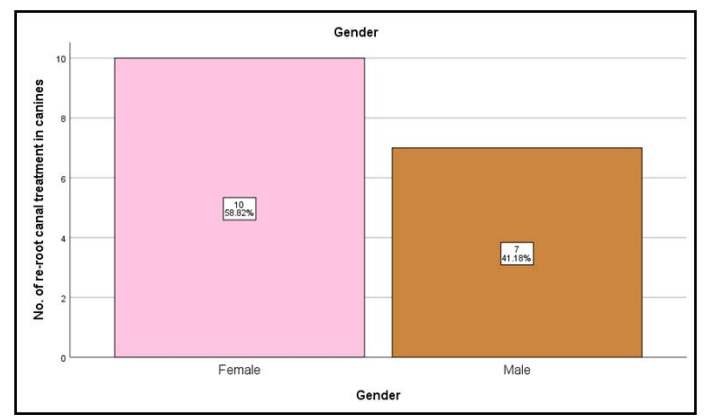

Figure 2. Shows the graphical representation of the number of re-root canal treatments done in maxillary and mandibular canines. $\mathrm{X}$-axis represents the tooth involved (mandibular canines(yellow), maxillary canines(green) and Y-axis represents the number of re-root canal treatments in canines. Incidence of re-root canal treatment was higher in maxillary canines $(82.4 \%)$ when compared to mandibular canines $(17.7 \%)$.

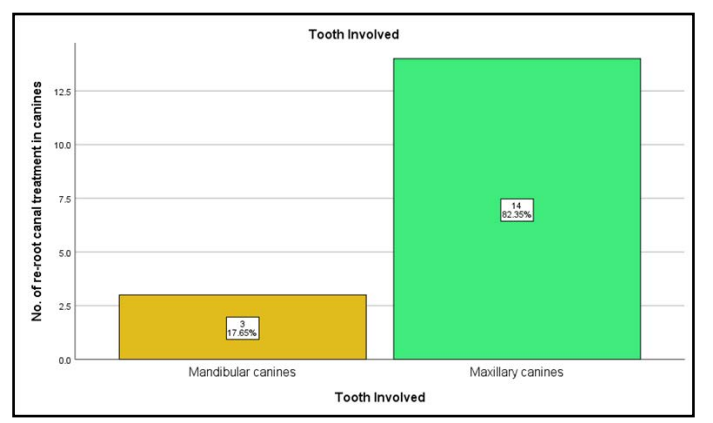


Figure 3. Shows graphical representation of various reasons for re-root canal treatment in canines. X-axis represents various reasons for re-root canal treatment (others- red, obturation short of apex- blue) and Y-axis represents the number of re-root canal treatment in canines. It shows re-root canal treatment due to obturation short of apex was higher $(64.7 \%)$ when compared to other reasons $(32.3 \%)$.

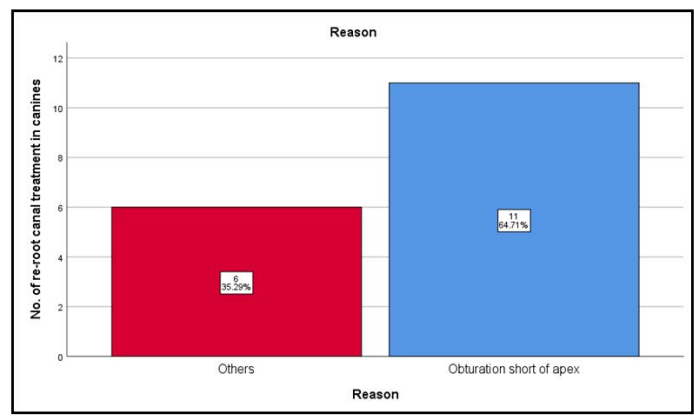

Figure 4. Shows graphical representation of reasons for re-root canal treatment of canines in males and females. X-axis represents the gender and Y-axis represents the number of re-root canal treatment in canines. Incidence of re-root canal treatment in canines due to obturation short of apex (blue) was higher in females compared to males. However, the results were statistically not significant (Pearson chi-square value- 0.298 , df- 1 , $p$ value- 0.585 ( $p>0.05$ ))

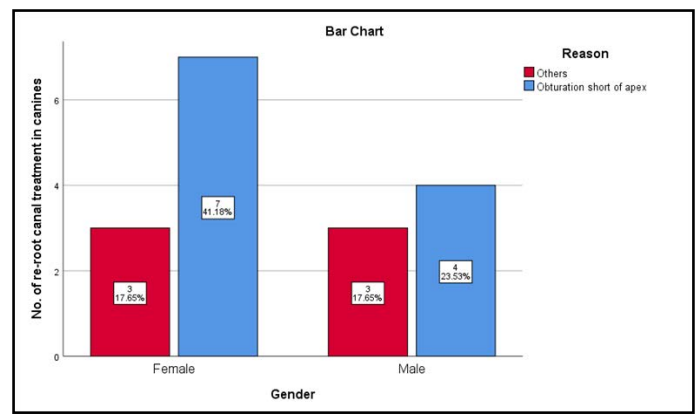

Figure 5. shows graphical representation of reasons for re-root canal treatment in maxillary canines and mandibular canines. $\mathrm{X}$-axis represents the tooth involved and $\mathrm{Y}$-axis represents the number of re-root canal treatment in canines. Incidence of re-root canal treatment in canines due to obturation short of apex (blue) were higher in mandibular canines when compared to maxillary canines. However, the results were statistically not significant (Pearson chisquare value- 0.006 , df value- $1, \mathrm{p}$ value- $0.938(\mathrm{p}>0.05))$.

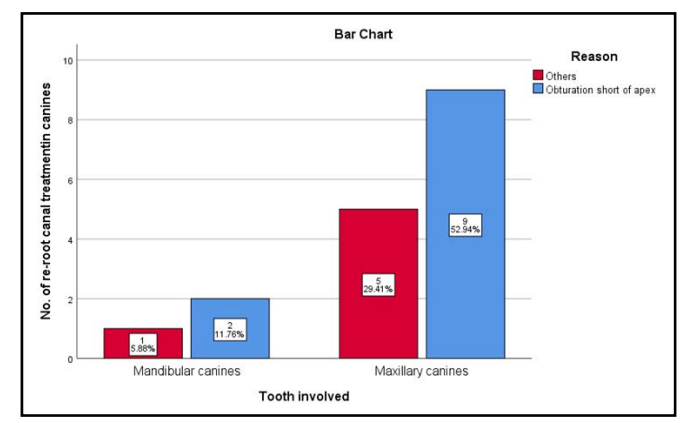

involved, $66.7 \%$ of mandibular canines and $64.3 \%$ of maxillary canines were retreated due to obturation short of apex (Figure 5). No statistically significant association was found between re-root canal treatment in canines due to obturation short of apex and tooth involved ( $p>0.05)$ (Figure 5).

There are various reasons for root canal treatment failure such as ledges, separated instruments, perforations, transportation, missed and blocked canals. All of these eventually influence the final outcome of root canal treatment [25]. Insufficient cleaning and inadequate sealing of the root canal system are the most common causes of endodontic failure $[14,26]$. Root canal obturation is an important phase in root canal treatment. Many studies have reported high rates of root canal treatment failure is due to inadequate canal preparation and obturation $[27,28]$.

In this study, we observed that $64.7 \%$ of canines underwent root canal retreatment due to obturation short of apex. This was in agreement with Akbar et al 8. His study reported the most common reason for endodontic failure was underfilling [8]. BarrieshiNusair et al and Peak et al., also reported under-filling as the most common reason for endodontic failure [29, 30]. They recorded more than $34 \%$ underfillings were observed in their study [29, 30]. This finding is contrary to the studies reported by Er et al and Dadresanfar et al who reported on $18 \%$ underfillings in their study [31].

The current study found that the mandibular canines had undergone a higher percentage of re-root canal treatment. This finding was contrary to a finding reported by Moura et al . She reported maxillary canines are more common to undergo retreatment [32]. Possible reasons may be due to different geographic locations and socioeconomic status of study population.

Obturation short of apex in teeth with longer root length is fairly common as some endodontic instruments are not able to reach the optimum working length for root canal preparation and obturation. This can be overcome with the use of longer endodontic instruments such as the $31 \mathrm{~mm} \mathrm{k}$-files to prepare the root canal. The obturation of teeth with longer root length may be difficult when using the conventional obturation technique. A study found that the Obtura II injectable technique obturated the root canal 
consistently to the working length, providing better obturation compared to the lateral condensation technique and the thermafil obturation technique [33]. This technique can be applied to improve the success of root canal treatment in teeth with longer root length.

\section{Limitation of this study}

This study has limitations as it was conducted as a university based study and may be subjected to researcher's personal bias and allowed only a limited population to be covered.

\section{Future Scope}

Extensive research needs to be done with a larger sample population. Future studies can include other factors which may influence need for retreatment of root canal in canines due to short of apex, such as the length of obturation from apex and duration of treated tooth.

\section{Conclusion}

Within the limits of this study, it is observed that the majority of root canal treated canines underwent retreatment is due to obturation short of apex. Most prevalent tooth to undergo retreatment due to obturation short of apex was mandibular canines.

\section{Acknowledgement}

We would like to express sincere gratitude to Saveetha Dental College and Hospital, Chennai for the contribution and involvement in this study.

\section{References}

[1]. Adebayo ET, Ahaji LE, Nnachetta RN, Nwankwo O, Akabogu-Okpeseyi $\mathrm{N}$, Yaya MO, et al. Technical quality of root canal fillings done in a Nigerian general dental clinic. BMC Oral Health. 2012 Oct 15;12:42. PMID: 23066650 .

[2]. Sjogren U, Hagglund B, Sundqvist G, Wing K. Factors affecting the longterm results of endodontic treatment. J Endod. 1990 Oct;16(10):498-504. PMID: 2084204.

[3]. Kerekes K, Tronstad L. Long-term results of endodontic treatment performed with a standardized technique. J Endod. 1979 Mar;5(3):83-90. PMID: 296248.

[4]. Kirkevang LL, Ørstavik D, Hörsted-Bindslev P, Wenzel A. Periapical status and quality of root fillings and coronal restorations in a Danish population. Int Endod J. 2000 Nov;33(6):509-15. PMID: 11307254.

[5]. Dugas NN, Lawrence HP, Teplitsky PE, Pharoah MJ, Friedman S. Periapical health and treatment quality assessment of root-filled teeth in two Canadian populations. Int Endod J. 2003 Mar;36(3):181-92. PMID: 12657144.

[6]. Segura-Egea JJ, Jiménez-Pinzón A, Poyato-Ferrera M, Velasco-Ortega E, Ríos-Santos JV. Periapical status and quality of root fillings and coronal restorations in an adult Spanish population. Int Endod J. 2004 Aug;37(8):52530. PMID: 15230905.

[7]. European Society of Endodontology. Quality guidelines for endodontic treatment: consensus report of the European Society of Endodontology. Int Endod J. 2006 Dec;39(12):921-30. PMID: 17180780.

[8]. Akbar I. Radiographic study of the problems and failures of endodontic treatment. Int J Health Sci (Qassim). 2015 Apr;9(2):111-8. PMID: 26309429.

[9]. Somalinga Amardeep N, Raghu S, Natanasabapathy V. Root canal morphology of permanent maxillary and mandibular canines in Indian population using cone beam computed tomography. Anat Res Int. 2014;2014:731859. PMID: 24895538.

[10]. Ramamoorthi S, Nivedhitha MS, Divyanand MJ. Comparative evaluation of postoperative pain after using endodontic needle and EndoActivator during root canal irrigation: A randomised controlled trial. Aust Endod J. 2015
Aug;41(2):78-87. PMID: 25195661.

[11]. Hussainy SN, Nasim I, Thomas T, Ranjan M. Clinical performance of resinmodified glass ionomer cement, flowable composite, and polyacid-modified resin composite in noncarious cervical lesions: One-year follow-up. J Conserv Dent. 2018 Sep-Oct;21(5):510-515. PMID: 30294112.

[12]. Noor S. Chlorhexidine: Its properties and effects. Research Journal of Pharmacy and Technology. 2016;9(10):1755-60.

[13]. Jose J, Subbaiyan H. Different Treatment Modalities followed by Dental Practitioners for Ellis Class 2 Fracture-A Questionnaire-based Survey. The Open Dentistry Journal. 2020 Feb 18;14(1).

[14]. Manohar MP, Sharma S. A survey of the knowledge, attitude, and awareness about the principal choice of intracanal medicaments among the general dental practitioners and nonendodontic specialists. Indian J Dent Res. 2018 Nov-Dec;29(6):716-720. PMID: 30588997.

[15]. Teja KV, Ramesh S. Shape optimal and clean more. Saudi Endodontic Journal. 2019 Sep 1;9(3):235.

[16]. Ramanathan S, Solete P. Cone-beam Computed Tomography Evaluation of Root Canal Preparation using Various Rotary Instruments: An in vitro Study. J Contemp Dent Pract. 2015 Nov 1;16(11):869-72. PMID: 26718293.

[17]. Siddique R, Sureshbabu NM, Somasundaram J, Jacob B, Selvam D. Qualitative and quantitative analysis of precipitate formation following interaction of chlorhexidine with sodium hypochlorite, neem, and tulsi. J Conserv Dent. 2019 Jan-Feb;22(1):40-47. PMID: 30820081.

[18]. Rajendran R, Kunjusankaran RN, Sandhya R, Anilkumar A, Santhosh R, Patil SR. Comparative Evaluation of Remineralizing Potential of a Paste Containing Bioactive Glass and a Topical Cream Containing Casein Phosphopeptide-Amorphous Calcium Phosphate: An in Vitro Study. Pesquisa Brasileira em Odontopediatria e Clínica Integrada. 2019;19.

[19]. Teja KV, Ramesh S, Priya V. Regulation of matrix metalloproteinase-3 gene expression in inflammation: A molecular study. Journal of conservative dentistry: JCD. 2018 Nov;21(6):592.

[20]. Janani K, Palanivelu A, Sandhya R. Diagnostic accuracy of dental pulse oximeter with customized sensor holder, thermal test and electric pulp test for the evaluation of pulp vitality: an in vivo study. Brazilian Dental Science. 2020 Jan 31;23(1):8-p.

[21]. Nandakumar M, Nasim I. Comparative evaluation of grape seed and cranberry extracts in preventing enamel erosion: An optical emission spectrometric analysis. J Conserv Dent. 2018 Sep-Oct;21(5):516-520. PMID: 30294113.

[22]. Rajakeerthi R, Ms N. Natural Product as the Storage medium for an avulsed tooth-A Systematic Review. Cumhuriyet Dental Journal. 2019;22(2):24956.

[23]. Kumar D, Antony S. Calcified Canal and Negotiation-A Review. Research Journal of Pharmacy and Technology. 2018;11(8):3727-30.

[24]. Ravinthar K. Recent advancements in laminates and veneers in dentistry. Research Journal of Pharmacy and Technology. 2018;11(2):785-7.

[25]. Eleftheriadis GI, Lambrianidis TP. Technical quality of root canal treatment and detection of iatrogenic errors in an undergraduate dental clinic. Int Endod J. 2005 Oct;38(10):725-34. PMID: 16164687.

[26]. Khan M, Rehman K, Saleem M. CAUSES OF ENDODONTIC TREATMENT FAILURE--A STUDY. Pakistan Oral \& Dental Journal. 2010 Jun $1 ; 30(1)$.

[27]. Estrela C, Bueno MR, Azevedo BC, Azevedo JR, Pécora JD. A new periapical index based on cone beam computed tomography. J Endod. 2008 Nov;34(11):1325-1331. PMID: 18928840.

[28]. Imfeld TN. Prevalence and quality of endodontic treatment in an elderly urban population of Switzerland. J Endod. 1991 Dec;17(12):604-7. PMID: 1820423.

[29]. Barrieshi-Nusair KM, Al-Omari MA, Al-Hiyasat AS. Radiographic technical quality of root canal treatment performed by dental students at the Dental Teaching Center in Jordan. J Dent. 2004 May;32(4):301-7. PMID: 15053913.

[30]. Peak JD, Hayes SJ, Bryant ST, Dummer PM. The outcome of root canal treatment. A retrospective study within the armed forces (Royal Air Force). Br Dent J. 2001 Feb 10; 190(3): 140-4. PMID: 11236917.

[31]. Er O, Sagsen B, Maden M, Cinar S, Kahraman Y. Radiographic technical quality of root fillings performed by dental students in Turkey. Int Endod J. 2006 Nov;39(11):867-72. PMID: 17014524.

[32]. Moura MS, Guedes OA, De Alencar AH, Azevedo BC, Estrela C. Influence of length of root canal obturation on apical periodontitis detected by periapical radiography and cone beam computed tomography. J Endod. 2009 Jun; 35(6): 805-9. PMID: 19482175.

[33]. Weller RN, Kimbrough WF, Anderson RW. A comparison of thermoplastic obturation techniques: adaptation to the canal walls. J Endod. 1997 Nov;23(11):703-6. PMID: 9587313 